Науковий вісник НЛтУ України
Scientific Bulletin of UNFU
https://nv.nltu.edu.ua
https://doi.org/10.15421/40280615
Article received 15.06.2018 p.
Article accepted 25.06.2018 p.
Удк 621.039.322

М. М. Семерак, С. С. Лис, О. Г. Юрасова

Національний університет "Львівська політехніка", м. Львів, Україна

\title{
АНАЛІЗ ОСНОВНИХ ЗАСОБІВ ЗАБЕЗПЕЧЕННЯ ВОДНО-ХІМІЧНОГО РЕЖИМУ АЕС
}

Водно-хімічний режим (ВХР) повинен бути спрямований на забезпечення і підтримання норм якості водного теплоносія i стану внутрішніх поверхонь обладнання основного контуру для досягнення безаварійної роботи устатковання АЕС. Водно-хімічний режим АЕС повинен забезпечувати безпечну кількість відкладень на поверхнях тепловиділяючих елементів i технологічних каналів, допустимі швидкості корозії конструкційних матеріалів основного пароводяного тракту, а також високу якість насиченої пари, що не спричиняє неприпустимих відкладень у турбіні. До засобів забезпечення водно-хімічного режиму АЕС відносять післямонтажну підготовку обладнання основних і допоміжних контурів, безперервне продування контуру багаторазової примусової циркуляції (КМПЦ) за номінальних режимів установок спецводоочищення (CВО-1); очищення всього потоку турбінного конденсату на фільтрах конденсатоочищення; підготовку додаткової води на хімводоочищення і на (CВО-4); очищення підживлювальної води на установках спеціального водоочищення (СВО-5), дегазацію турбінного конденсату і живильної води в деаераторі турбіни; хімічний контроль, що полягає у визначенні нормовано контрольованих показників водного теплоносія для установлення рівня його якості та оцінювання засобів забезпечення водно-хімічного режиму. Тому від ступеня чистоти води і водяної пари та рівня підтримки корекційних добавок залежить надійна робота обладнання.

Ключові слова: живильна вода; хімводоочищення; спеціальне водоочищення; турбінний конденсат.

Вступ. Надійність роботи будь-якої АЕС залежить від водно-хімічного режиму (ВХР) не тільки основного контуру, але і контурів охолодження і очищення допоміжних систем. Нормування показників якості робочих середовищ допоміжних систем потрібно для забезпечення корозійної стійкості конструкційних матеріалів контурів до суцільної місцевої контактної корозії з урахуванням міцнісних характеристик, а також економічної доцільності (Stiazhkin et al., 2003).

Для оцінювання і прогнозування корозійного стану передусім встановлюють контроль за вмістом у робочому середовищі заліза (Gostkov, 1999; Arkhypenko, Hladyshev \& Masko, 2003). Для робочого середовища басейнів витримки додатково встановлюють контроль за вмістом масла, яке може потрапляти в басейни разом 3 обмивальними розчинами з підлоги центрального залу під час завантаження касет.

Засоби забезпечення водно-хімічного режиму (ВХP) забезпечують підтримку нормованих показників якості теплоносія і допустимий стан внутрішніх поверхонь обладнання і трубопроводів основного контуру.

Викладення основного матеріалу дослідження. Для підтримки нормального режиму роботи контурів схем "Л" і "Д", контуру СУЗ, промконтуру реакторного відділення, басейну-барботера передбачені спеціальні схеми очищення на іонообмінних фільтрах - CBO-15, CBO-3, CBO-13, CBO-2 (Gostkov, 1999). Дані щодо якості води допоміжних контурів наведено в табл. 1.

У межах допустимих відхилень від норм ВХР допоміжних контурів допускається зниження продуктивності, або тимчасове відключення установки очищення води контуру СУЗ за дотримання нормованих показників якості води в контурі і за наявності автохімконтролю електричної провідності води.

Перше заповнення систем: басейнів витримки, контурів охолодження схем "Л" і "Д", проміжних контурів проводять конденсатом, якість якого має відповідати нормам, наведеним у табл. 1.

Допускається перевищення не більше ніж на $50 \%$ від норм вмісту сполук міді і кисню в системі охолодження статора генератора (СОСТГ) впродовж перших чотирьох діб під час пуску турбогенератора після ремонту, а також у разі знаходження в резерві.

Хімводоочищення на АЕС є одним із засобів підтримки водно-хімічного режиму станції і слугує першочерговим для заповнення КМПЦ, КПТ, а також для заповнення безповоротних втрат пари і конденсату АEC.

Хімводоочищення складається 3 установки попереднього очищення в конструкції трьохступінчастого знесолення, розташованих поза зоною режиму, на ОВК.

Інформація про авторів:

Семерак Михайло Михайлович, д-р. техн. наук, професор, завідувач кафедри теплоенергетики, теплових і атомних електричних станцій. Email: lysss@ukr.net

Лис Степан Степанович, канд. техн. наук, ст. викладач, кафедра теплоенергетики, теплових і атомних електричних станцій. Email: lysss@ukr.net; https://orcid.org/0000-0002-7359-1177

Юрасова Оксана Георгївна, ст. викладач, кафедра теплоенергетики, теплових і атомних електричних станцій. Email: oksjanchyk@gmail.com; https://orcid.org/0000-0001-9930-9152

Цитування за ДСту: Семерак М. М., Лис С. С., Юрасова О. Г. Аналіз основних засобів забезпечення водно-хімічного режиму АЕС. Науковий вісник НЛТУ України. 2018, т. 28, № 6. С. 81-83.

Citation APA: Semerak, M. M., Lys, S. S., \& Yurasova, O. H. (2018). Analysis of the main means of ensuring the water chemistry conditions of the nuclear power plant. Scientific Bulletin of UNFU, 28(6), 81-83. https://doi.org/10.15421/40280615 
Табл. 1. Нормовані показники якості води допоміжних контурів

\begin{tabular}{|c|c|c|c|c|c|c|c|}
\hline Система & $\mathrm{pH}$ за $25^{\circ} \mathrm{C}$ & $\begin{array}{c}\mathrm{C} 1^{-}, \\
\text {мкг/дм } \\
\end{array}$ & $\begin{array}{c}\mathrm{Fe}^{3+}, \\
\text { мкг/дм }\end{array}$ & $\begin{array}{c}Ж_{\mathrm{o}}, \\
\text { мкг-екв/дм }\end{array}$ & $\begin{array}{c}\chi 25 \\
\mathrm{M \kappa CM} / \mathrm{cm}\end{array}$ & $\begin{array}{c}\mathrm{Al}^{3+} \\
\text { мкг/дм }\end{array}$ & $\begin{array}{c}\text { Нафтопродукти, } \\
\text { мкг/дм }^{3}\end{array}$ \\
\hline Охолоджувальна вода контуру СУЗ & $4,5 \div 6,2$ & 50 & 100 & - & - & 100 & - \\
\hline $\begin{array}{l}\text { Система біологічного захисту (схеми } \\
\text { "Л" і "Д") }\end{array}$ & $\begin{array}{c}\mathrm{H} \\
6,5 \div 10\end{array}$ & $\begin{array}{c}\mathrm{H} \\
200\end{array}$ & $\begin{array}{c}\kappa \\
2000\end{array}$ & - & $\begin{array}{c}\mathrm{K} \\
10 \\
\end{array}$ & - & - \\
\hline $\begin{array}{l}\text { Вода басейну витримки касет і техно- } \\
\text { логічних каналів (БВК, БВТК) }\end{array}$ & $\begin{array}{c}\mathrm{H} \\
5,54 \div 8,0\end{array}$ & $\begin{array}{c}\mathrm{H} \\
100\end{array}$ & $\begin{array}{c}\mathrm{K} \\
1000 \\
\end{array}$ & - & $\begin{array}{c}\mathrm{H} \\
3,0\end{array}$ & - & $\begin{array}{c}\Gamma \\
200 \\
\end{array}$ \\
\hline $\begin{array}{l}\text { Охолоджувальна вода промконтуру ре- } \\
\text { акторного відділу (ПКРО), тепломере- } \\
\text { жі, парогенератора }\end{array}$ & $6,0 \div 10,0$ & $\begin{array}{c}\mathrm{H} \\
100\end{array}$ & $\begin{array}{c}\mathrm{K} \\
2000\end{array}$ & - & $\begin{array}{c}\mathrm{K} \\
3,0\end{array}$ & - & - \\
\hline Вода басейну-барботера (ББ) & $\begin{array}{c}\mathrm{H} \\
5,5 \div 8,0\end{array}$ & $\begin{array}{c}\mathrm{H} \\
150\end{array}$ & $\begin{array}{c}\mathrm{K} \\
100 \\
\end{array}$ & $\begin{array}{c}\mathrm{K} \\
50\end{array}$ & $\begin{array}{c}\mathrm{H} \\
2,0\end{array}$ & - & $\begin{array}{c}\Gamma \\
200\end{array}$ \\
\hline $\begin{array}{l}\text { Система охолодження статора генера- } \\
\text { тора (СОСТГ) }\end{array}$ & $8,5 \pm 0,5$ & - & $\begin{array}{l}\mathrm{Cu}^{2+} \\
200\end{array}$ & $\mathrm{O}_{2} \leq 400$ & 5 & - & - \\
\hline $\begin{array}{l}\text { Вода промконтуру тепломережі } \\
\text { (ПКТС) }\end{array}$ & $6,0 \div 10,0$ & 100 & 2000 & - & 3 & - & - \\
\hline Вторинна пара випарників машзалу & - & - & 10 & - & - & $\begin{array}{c}\mathrm{Na}^{+} \\
30\end{array}$ & $\begin{array}{c}\mathrm{SiO}_{3}^{2-} \\
10\end{array}$ \\
\hline
\end{tabular}

Хімічні реагенти, використовувані в технологічному процесі на установках XВО (СВО), подаються зі складу хімреагентів по естакаді трубопроводів.

Установка попереднього очищення містить освітлювач (I ступінь) та механічні фільтри (II ступінь). Освітлена вода після механічних фільтрів попереднього очищення надходить на катіонітові фільтри I ступеня (Gostkov, 1999) (рисунок) ФКІ-081 -084, де відбувається видалення з води всіх катіонів жорсткості $\left(\mathrm{Ca}^{2+}, \mathrm{Mg}^{2+}\right)$ i $\mathrm{Na}^{+}$із заміною їх на іони водню $\mathrm{H}^{+}$, що містяться в катіоніті. Внаслідок обміну в фільтраті з'являються вільні мінеральні (сильні) кислоти (сірчана, соляна, азотна), а також у недисоційованому вигляді кремнієва і вугільна кислоти.

В аніонітних фільтрах I ступеня (ФАІ-101 $\div 104)$, куди далі надходить вода, відбувається заміна аніонів сильних кислот $\left(\mathrm{SO}_{4}{ }^{3-}, \mathrm{Cl}^{-}, \mathrm{NO}_{3}^{-}\right)$на аніони гідроксилу $\left(\mathrm{OH}^{-}\right)$, що містяться в аніоніті. Ті, що перейшли в роз- чин унаслідок обміну, іони $\mathrm{H}^{+}$i $\mathrm{OH}^{-}$зв'язуються в молекули води. Вода направляється в декарбонізатор, де відбувається видалення 3 оброблюваної води розчиненої вугільної кислоти. Внаслідок декарбонізації створюються сприятливі умови для роботи аніонітних фільтрів II ступеня.

На катіонітних фільтрах II ступеня (ФКІІ-161 $\div 162$ ), на які оброблювана вода подається з баків декарбоніза-

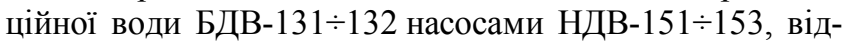
бувається заміна катіонів жорсткості, що проскочили у фільтрат після I ступеня на іони $\mathrm{H}^{+}$, що містяться в катіоніті. Далі вода надходить на аніонітні фільтри II ступеня ФДП- $171 \div 172$, де відбувається сорбція аніонів кремнієвої кислоти і залишків вугільної кислоти. Внаслідок обміну відбувається повне знекремнювання води. ІІІ ступінь знесолення - фільтри змішаної дії ФСД$181 \div 182$, де відбувається повне і глибше знесолення та знекремнювання води.

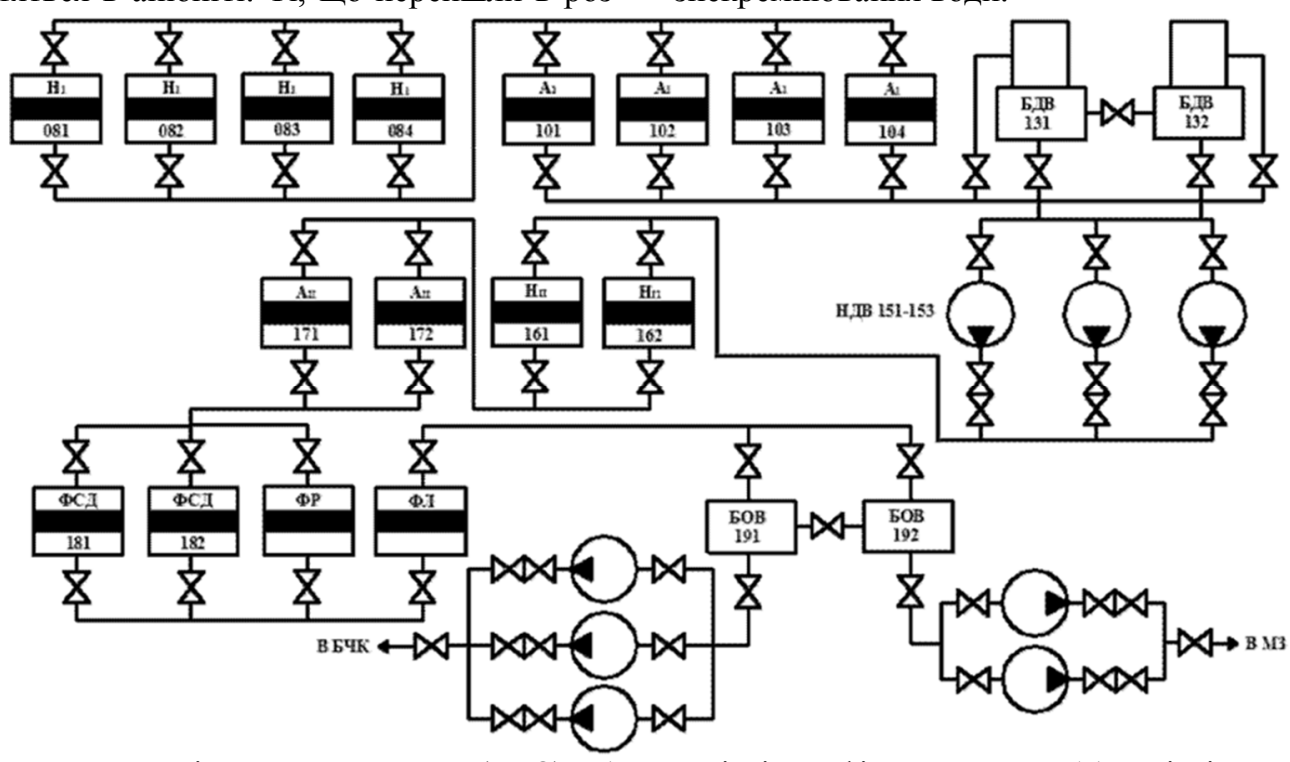

Рисунок. Установка трьохступінчастого знесолення (XBO): Н1 - Н-катіонітний фільтр I ступеня; А1 - аніонітний фільтр I ступеня; БДВ - бак декарбонізації води; НДВ - насоси декарбонізованої води; НІІ - Н-катіонітний фільтр II ступеня; АІІ - аніонітний фільтр ІІ ступеня; ФСД - фільтр змішаної дії; ФР - фільтр регенератор; ФЛ - фільтр-уловлювач іонітів; БОВ - бак знесоленої води; БЧК бак чистого конденсату; МЗ - машзал

Хімознесолена вода після ФСД через фільтр-уловлювач іонітів, де проходить уловлювання іонітів при пошкодженні НДРУ, подається в баки знесоленої води БОВ-191 192, звідки насосами знесоленої води подається в БЧК для заповнення та підживлення контуру, а насосами подається в машзал для підживлення системи охолодження статора турбогенераторів і на первин- не заповнення контурів. Показники якості знесоленої води XВО (Gostkov, 1999) наведено в табл. 2.

Висновки. Доведено, що засоби забезпечення водно-хімічного режиму забезпечують підтримку нормованих показників якості теплоносія і допустимий стан внутрішніх поверхонь обладнання та трубопроводів основного контуру. 
Табл. 2. Норми якості води ХВО

\begin{tabular}{|c|c|c|c|}
\hline Показник & $\begin{array}{c}\text { Коагульована } \\
\text { вода }\end{array}$ & \begin{tabular}{|c} 
Декарбонізо- \\
вана вода
\end{tabular} & $\begin{array}{c}\text { Хімознесо- } \\
\text { лена вода }\end{array}$ \\
\hline pH, од. & $6,5 \div 7,0$ & - & $5,5 \div 7,5$ \\
\hline $\begin{array}{c}\text { Питома електропро- } \\
\text { відність, мкСм/см }\end{array}$ & $\mathrm{H} / \mathrm{H}$ & - & 0,8 \\
\hline Прозорість, \% & $95 \div 98$ & - & - \\
\hline Окислюваність, \% & $\begin{array}{l}\text { Зменшення } \\
\text { на } 50 \div 80 \%\end{array}$ & - & - \\
\hline $\begin{array}{l}\text { Лужність, мг- } \\
\text { екв/дм }{ }^{3} \\
\end{array}$ & $0,5 \div 0,7$ & 0,05 & - \\
\hline $\begin{array}{c}\text { Вуглекислота, } \\
\text { мг/дм }{ }^{3}\end{array}$ & - & $5 \div 10$ & - \\
\hline $\mathrm{Na}^{+}$, мкг/дм ${ }^{3}$ & - & - & 10 \\
\hline $\mathrm{Fe}^{3+}$, мкг/дм ${ }^{3}$ & $100 \div 150$ & - & 40 \\
\hline $\mathrm{SiO}_{3}{ }^{2-}$, мкг/дм ${ }^{3}$ & - & - & 30 \\
\hline $\mathrm{Cl}^{-}$, мкг/дм ${ }^{3}$ & - & - & 20 \\
\hline $\begin{array}{c}\text { Нафтопродукти, } \\
\text { мкг/дм }\end{array}$ & - & - & 100 \\
\hline
\end{tabular}

Встановлено, що перше заповнення систем проводиться конденсатом, якість якого має відповідати нормам, наведеним у табл. 1. Допускається перевищення не більше ніж на $50 \%$ від норм вмісту сполук міді і кисню в системі охолодження статора генератора (СОСТГ) впродовж перших чотирьох діб при пуску турбогенератора після ремонту, а також у разі знаходження в резерві.
Під час роботи блоку потужністю 100 МВт і вмісту продуктів корозії в межах норми в реактор за добу надходить до 2,5 кг заліза і до 0,5 кг міді. Перехід продуктів корозії в живильну воду помітно знижується у разі безперервного знесолення води на конденсатоочищенні, розрахованої на очищення всього (100\%) конденсату.

Отже, хімводоочищення на АEC $є$ одним із засобів підтримки водно-хімічного режиму станції і слугує першочерговим для заповнення КМПЦ, КПТ, а також для заповнення безповоротних втрат пари і конденсату АЕС.

\section{Перелік використаних джерел}

Arkhypenko, O. V., Hladyshev, V. M., \& Masko, O. M. (2003). Udoskonalennia vodno-khimichnoho rezhymu 2 konturu na AES Ukrainy. Yaderni ta radiatsiini tekhnolohii, 3(3), 53-57. [In Ukrainian].

Gostkov, V. V. (1999). Rezhimy i normy ekspluatatcii oborudovaniia po khimiko-radiatcionnomu tcekhu AES. Ivanovo: Ivan. gos. energ. un-t. 258 p. [In Russian].

Stiazhkin, P. S., Kritckii, V. G., et al. (2003). Khemometricheskii analiz sviazi nadezhnosti elementov oborudovaniia AES so znacheniiami normiruemykh pokazatelei kachestva VKHR. Mezhdunarodnoe nauchno-tekhnicheskoe soveshhanie "Vodnokhimicheskii rezhim AES", Smolenskaia AES, 13-17 october, (pp. 98-105). VNIIAES. [In Russian].

М. М. Семерак, С. С. Лыс, О. Г. Юрасова

Наииональный университет "Львовская политехника", г. Львов, Украина

\section{АНАЛИЗ ОСНОВНЫХ СРЕДСТВ ОБЕСПЕЧЕНИЯ ВОДНО-ХИМИЧЕСКОГО РЕЖИМА АЭС}

Водно-химический режим (ВХР) должен быть направлен на обеспечение и поддержание норм качества водного теплоносителя и состояния внутренних поверхностей оборудования основного контура с целью достижения безаварийной работы оборудования АЭС. Водно-химический режим АЭС должен обеспечивать безопасное количество отложений на поверхностях тепловыделяющих элементов и технологических каналов, допустимые скорости коррозии конструкционных материалов основного пароводяного тракта, а также высокое качество насыщенного пара, не вызывает недопустимых отложений в турбине. К средствам обеспечения водно-химического режима АЭС относят послемонтажную подготовку оборудования основных и вспомогательных контуров, непрерывную продувку контура многократной принудительной циркуляции (КМПЦ) при номинальных режимах установок спецводоочистки (CBO-1); очистку всего потока турбинного конденсата на фильтрах конденсатоочистки; подготовку добавочной воды на химводоочистки и на (CBO-4); очистку подпиточной воды на установках специальной водоочистки (CBO-5), дегазацию турбинного конденсата и питательной воды в деаэраторе турбины; химический контроль, заключающийся в определении нормировано контролируемых показателей водного теплоносителя с целью установления уровня его качества и оценки средств обеспечения водно-химического режима. Поэтому от степени чистоты воды и водяного пара и уровня поддержки коррекционных добавок зависит надежная работа оборудования АЭС.

Ключевые слова: питательная вода; химводоочистка; специальная водоочистка; турбинный конденсат.

M. M. Semerak, S. S. Lys, O. H. Yurasova Lviv Polytechnic National University, Lviv, Ukraine

\section{ANALYSIS OF THE MAIN MEANS OF ENSURING THE WATER CHEMISTRY CONDITIONS} OF THE NUCLEAR POWER PLANT

The water chemistry conditions should be aimed at ensuring and maintaining the quality standards of the water coolant and the condition of the internal surfaces of the main circuit equipment in order to achieve trouble-free operation of the nuclear power plant (NPP) equipment. The quality of the coolant has a decisive influence on the reliability of the plant, but their verification is necessary, both for monitoring the operation of individual cleaning systems, and for assessing the optimality of the entire complex. The increase in the limiting values of the monitored indicators may be a signal of a violation of the normal operation of a number of systems, even with the support of the standardized indicators within specified limits. The quality of the coolant in normal operation of nuclear power plants must comply with the norms. The water chemistry conditions of the nuclear power plant must ensure a safe amount of deposits on the surfaces of fuel elements and technological channels, the permissible corrosion rates of the structural materials of the main steam-water path, and the high quality of saturated steam, without causing unacceptable deposits in the turbine. To the means of ensuring the water chemistry conditions of NPPs include post-installation preparation of equipment for main and auxiliary circuits, continuous blowing of the circuit of multiple forced circulation (MFC) under nominal conditions of special water treatment plants (SWTP-1); purification of the entire turbine condensate stream on condensate cleaning filters; preparation of additional water for chemical water purification and for (SWTP-4); cleaning of make-up water in special water treatment plants (SWTP-5), degassing of turbine condensate and feedwater in the turbine deaerator; chemical control, which means the determination of the standardly controlled indicators of the water coolant in order to establish the level of its quality and to assess the means of ensuring the water chemistry conditions. Therefore, reliable operation of nuclear power plant equipment depends on the degree of purity of water and water vapour and the level of support of corrective additives.

Keywords: feedwater; chemical water cleaning; special water cleaning; turbine condensate. 